\title{
Weekly Paclitaxel Combined with Carboplatin Versus the Standard Every 3-Weeks Paclitaxel and Carboplatin for Elderly Patients with Previously Untreated Advanced Non-Small Cell Lung Cancer.
}

\author{
Hala Mohamed El-Shenshawy, Saleh Taema, Eman El-Zahaf, Wafaa El-Beshbeshi, \\ Doaa Sharaf Eldeen and Amal Fathy ${ }^{1}$
}

\author{
${ }^{1}$ Departments of Clinical Oncology and Nuclear Medicine, Thoracic Medicine, Faculty of Medicine \\ Mansoura University
}

Background: Paclitaxel and platinum-based chemotherapy is considered to be a standard approach for locally advanced and metastatic Non-Small Cell Lung Cancer (NSCLC). In recent years, paclitaxel on a weekly schedule in combination with carboplatin has been widely used because it is associated with a lower incidence of neuropathy and myelosuppression. Otherwise, only a few studies are available in elderly patients with NSCLC. Purpose: The aim of our study was to evaluate the efficacy and safety of weekly paclitaxel combined with carboplatin compared with the classic 3-weekly schedule of paclitaxel and carboplatin as initial therapy and the feasibility of subsequent maintenance therapy versus observation in elderly patients with locally advanced ( stage IIIB) and metastatic (stage IV) NSCLC.

Patients and Methods: Ninty patients $\geq 65$ years with stage IIIB-IV NSCLC were randomly assigned to one of the following arms: arm1, paclitaxel $90 \mathrm{mg} / \mathrm{m}^{2}$ weekly for 3 of 4 weeks with carboplatin (area under the curve $\{$ AUC $\}=6$ ) on day 1 of each 4 week cycle and arm 2, paclitaxel $200 \mathrm{mg} / \mathrm{m}^{2}$ with carboplatin (AUC=6) on day 1 of each 3-week. After four cycles of chemotherapy, those with objective response or stable disease were randomized to weekly paclitaxel $\left(70 \mathrm{mg} / \mathrm{m}^{2}, 3\right.$ of 4 weeks) or observation as maintenance therapy. Primary end point was response while second end points included survival and toxicity.

Results: Eighty-six patients were evaluable for response, overall responses were recorded in $42.9 \%$ in arm 1 versus $31.8 \%$ in arm 2; stable disease was $38.1 \%$ in arm 1 versus $27.3 \%$ in arm 2 and progressive disease was $19 \%$ in arm 1 versus $40.9 \%$ in arm 2 . The median time to progression and median survival times were 7 months and 10.8 months in arm 1 versus 5.6 months and 9 months in arm 2, respectively. The 1-year survival rates were $47.6 \%$ in arm 1 versus $36.4 \%$ in arm 2 . Grade $3 / 4$ anemia was more common in arm $1(23.8 \%)$ than arm $2(9.1 \%)$. Grade $3 / 4$ neutropenia and febrile neutropenia occurred in $14.3 \%$ and $4.7 \%$ in arm 1 versus $22.7 \%$ and $9.1 \%$ in arm 2 . Grade $2 / 3$ neuropathy occurred in $4.7 \%$ in arm 1 versus $13.6 \%$ in arm 2 .

Conclusions: Efficacy was similar between the weekly regimen and the standard regimen of carboplatin and paclitaxel for elderly patients with advanced NSCLC and may be advantageous based on its favorable tolerability profile.

Key words: Elderly, non-small cell lung cancer, Paclitaxel, carboplatin.

Corresponding Author: wafaa el-beshbeshi

E-mail: wafaaelbeshbishi@yahoo.com

\section{INTRODUCTION}

Lung cancer is the most common cause of cancerrelated deaths in Western countries ${ }^{1}$. Non-small cell lung cancer (NSCLC) constitutes approximately $80 \%$ of all cases of lung cancer ${ }^{2}$. More than $50 \%$ of advanced NSCLC occurs in people aged $>65$ years $^{3}$, with median age at diagnosis of 70 years ${ }^{4}$.

Treatment of advanced NSCLC is palliative; the aim is to prolong survival with less deterioration in quality of life5. The recommended first-line treatment of advanced NSCLC currently involves platinumbased two-drug combination chemotherapy ${ }^{6}$. However, the efficacy of platinum-based doublets in elderly (aged $\geq 70$ years) patients with advanced NSCLC has not been studied extensively ${ }^{7}$. Therefore, the safety and efficacy data generated from randomized clinical trials cannot be extrapolated to elderly NSCLC patients. The choice of chemotherapy regimen for elderly NSCLC patients is influenced by both physician and patient-related factors. Perception of higher toxicity and lower efficacy in elderly patients by both the treating physician and the patient may result in suboptimal therapeutic selections. It is therefore important that elderly patients are adequately represented in clinical trials and it is also important 
Kasr-El-Aini Journal Of Clinical Oncology And Nuclear Medicine

Vol. 7 | No. 3-4 2011

Weekly Paclitaxel Combined with...

to conduct prospective studies exclusively in elderly patients. Treatment of elderly patients with systemic chemotherapy may be limited by various factors such as comorbid illnesses, physiologic changes in functional status, organ function and drug pharmacokinetics ${ }^{8}$.

Randomized clinical trials have established the utility of single-agent chemotherapy in elderly patients ${ }^{9,10}$. The elderly Lung Cancer Vinorelbine Study compared treatment with vinorelbine plus best supportive care to best supportive care alone ${ }^{11}$. Although the study did not complete its planned accrual, both survival and quality of life benefits were noted for the elderly patients treated with chemotherapy. The Multi-center Italian Lung Cancer Elderly Study compared single-agent therapy with vinorelbine or gemcitabine with the combination of the same drugs ${ }^{12}$. There was no added benefit when the two drugs were given in combination compared with single-agent therapy alone. However, toxicity was more pronounced with the combination regimen. Because platinum-based doublet regimens are superior to singleagent therapy with either a platinum compound or a novel agent alone ${ }^{13-16}$, there is a need to evaluate platinumbased combination regimens in elderly patients.

The dosing regimen for paclitaxel exists in several different permutations; the most common ones being every-3-week or weekly schedules. Studies using weekly single-agent paclitaxel have shown that this schedule is well tolerated and provides greater dose intensity when compared with the more conventional schedules. Chang et al. ${ }^{20}$ and Akerley et al. ${ }^{21}$ have reported results of trials using the weekly schedule to treat patients with advanced NSCLC; they achieved response rates of $32 \%$ and $39 \%$, respectively. Rossi et al. ${ }^{22}$ reported response rate of $37.5 \%$ with weekly paclitaxel in elderly patients with advanced NSCLC. However, weekly paclitaxel in elderly patients with advanced NSCLC in Fidias et al. $^{23}$ study had an overall response rate of $23 \%$, median time to failure of 5.2 months, median survival time of 10.3 months and survival rates after 1 and 2 years of $45 \%$ and $22 \%$, respectively, and in Yasuda et al. ${ }^{24}$ study had an overall response rate of $49 \%$ and median survival time of 55 weeks.

The combination of paclitaxel of $\left(225 \mathrm{mg} / \mathrm{m}^{2}\right)$ and carboplatin (area under the curve $\{$ AUC $\}=6$ ) administered every 3 weeks is the most commonly used chemotherapy regimen in the United States for treatment of advanced and metastatic NSCLC. The response rate with 3-weeks paclitaxel and carboplatin ranges from $17 \%$ to $25 \%$, with median survival times averaging approximately 8 months $\mathrm{s}^{25-27}$. Although the regimen is well tolerated, it is associated with a $10 \%$ to $17 \%$ incidence of neuropathy ${ }^{25-27}$. Suresh et al. ${ }^{28}$ reported overall response rate of $19 \%$, median survival duration of 31 weeks and 1-year survival rate of $33 \%$ and grade 3 neuropathy of $9.5 \%$ with 3 -weeks paclitaxel and carboplatin in elderly patients with advanced NSCLC. Sakakibara et al. $^{29}$ reported an overall response rate of $53 \%$ and median progression-free survival of 5.6 months and grade $3 / 4$ neuropathy of $25 \%$ with 3 -week paclitaxel and carboplatin in elderly patients with advanced NSCLC.

Weekly regimens of paclitaxel in combination with carboplatin were developed in an attempt to increase the overall efficacy and decrease the expected toxicities. Another potential advantage to administration of paclitaxel at frequent, low dose is its ability to inhibit tumor neoangiogenesis ${ }^{30}$. Suresh et $a l .{ }^{8}$ reported that administration of carboplatin every 4 weeks in combination with weekly paclitaxel for 3 of 4 weeks associated with the best therapeutic index among other different weekly schedules. The median survival was 11.3 months, the 1 -year survival rate was $47 \%$, the overall response rate was $32 \%$ and grade $3 / 4$ neuropathy was $5 \%$ with this regimen. The impressive safety profile of the weekly schedule makes this regimen worthy of evaluation for the treatment of elderly NSCLC patients. Therefore, we performed a randomized study to determine the efficacy and toxicity of the weekly schedules of paclitaxel in combination with carboplatin and compare its results with the standard every 3-weeks regimen for elderly patients with advanced or metastatic NSCLC.

\section{PATIENTS AND METHODS}

\section{Patients Selection:}

Between January 2003 and October 2008, 90 previously untreated elderly patients with advanced NSCLC who attended to department of clinical oncology and nuclear medicine at Mansoura University Hospital and department of clinical oncology at Mansoura Health Inssurrance Clinic, were randomly assigned onto the initial therapy phase of our prospective study. Previously untreated patients were eligible for the study if they were at least 65 years of age and had histologically or cytologically confrmed, inoperable, stage IIIB or IV NSCLC. Patients had to have at least one bidimensionally measurable lesion that had not been previously irradiated. Three patients in arm 1 and one patient in arm 2 refuse to continue in our randomized study, only 86 patients (42 patients in arm 1 and 44 patients in arm 2) completed at least two cycles of study treatment and were assessable for survival, tumor response and toxicity.

The Eastern Cooperative Oncology Group (ECOG) performance status (PS) had to be 0 to 2 , and patients had to have a life expectancy of $\geq 12$ weeks and 
Kasr-El-Aini Journal Of Clinical Oncology And Nuclear Medicine

Vol. 7 | No. 3-4 2011

adequate hematologic (absolute granulocyte count $\geq$ $1,500 / \mathrm{IL}$ and platelets $\geq 100,000 / \mathrm{IL}$ ), renal (creatinine $\leq 2 \mathrm{mg} / \mathrm{dL}$ ), and hepatic (AST/ALT $\leq 2.5 \mathrm{x}$ upper limit of normal and bilirubin $\leq 1.5 \mathrm{x}$ upper limit of normal) function. Prior chemotherapy was not allowed. Patients with measurable neuropathy, active serious infection, or other serious underlying medical conditions were ineligible. Written informed consent was obtained from all patients before enrollment.

Pretreatment evaluations included a complete physical examination, a complete blood count with differential, platelet counts, hemoglobin, and the following serum chemistry tests: Electrolytes, blood urea nitrogen, creatinine, alkaline phosphatase, SGOT, and total and direct bilirubin. All sites of disease were documented by computed tomography or magnetic resonance imaging. Brain computed tomography and bone scan were performed as clinically indicated.

\section{Treatment Plan:}

Patients enrolled onto this study received an initial phase of therapy that was followed by maintenance therapy for those patients achieving an objective response or stable disease with initial therapy. In the initial therapy phase, patients on arm 1 received paclitaxel $90 \mathrm{mg} / \mathrm{m}^{2}$ weekly for 3 of 4 weeks over 3 $\mathrm{h}$ with carboplatin (area under the curve $\{$ AUC $\}=6$ ) on day 1 of each 4 week cycle; and patients on arm 2 received paclitaxel $200 \mathrm{mg} / \mathrm{m}^{2}$ over $3 \mathrm{~h}$ with carboplatin $(\mathrm{AUC}=6)$ on day 1 every 3 weeks. Premedication administered 30 to 60 minutes before paclitaxel consisted of dexamethasone $20 \mathrm{mg}$ intravenously (IV), diphenhydramine $50 \mathrm{mg} \mathrm{IV}$, and a histamine 2 blocker (such as cimetidine $300 \mathrm{mg}$ or ranitidine $50 \mathrm{mg} \mathrm{IV}$ ).

Patients who experienced complete response, partial response, or stable disease after four cycles of therapy in either arm of the study were randomized to the maintenance phase of therapy with weekly paclitaxel or observation. Each cycle of maintenance chemotherapy consisted of paclitaxel $70 \mathrm{mg} / \mathrm{m}^{2}$ weekly over $3 \mathrm{~h}$ for 3 of 4 weeks. Maintenance therapy continued until disease progression, development of intercurrent illness, intolerable toxicity, patient refusal of further treatment, or investigator decision to terminate treatment.

A maximum of two dose-level reduction was permitted per patient in the initial phase, but only one reduction was allowed during the maintenance phase. During the initial phase, the dose of carboplatin was reduced to achieve AUC of 5 and $4 \mathrm{mg} / \mathrm{mL}$. min, respectively, with each reduction. In arm 1, paclitaxel dose was reduced to $85 \mathrm{mg} / \mathrm{m}^{2}$ and $70 \mathrm{mg} / \mathrm{m}^{2}$, respectively, with each reduction. In arm 2 , paclitaxel was reduced to $175 \mathrm{mg} / \mathrm{m}^{2}$ and $150 \mathrm{mg} / \mathrm{m}^{2}$, respectively, with each reduction, For the maintenance phase, paclitaxel dose could be reduced to $50 \mathrm{mg} / \mathrm{m}^{2}$. Both paclitaxel and carboplatin were reduced by one dose level if the ANC nadir was no more than $800 / \mu \mathrm{L}$ and/or the platelet count were $50,000 / \mu \mathrm{L}$ or lower. Paclitaxel was reduced by one level for grade 2 neuropathy, and patients were removed from the study for grade 3 or worse, neuropathy. Paclitaxel was withheld for grade 3 fatigue, arthralgias, or myalgias until resolution to no worse than grade 2 and then resumed with a reduction of dose by one level. Paclitaxel was decreased by one dose level for bilirubin levels between 1.5 and $2.0 \mathrm{mg} /$ $\mathrm{dL}$, or withheld for levels higher than $2.0 \mathrm{mg} / \mathrm{dL}$ until resolution to no more than $2.0 \mathrm{mg} / \mathrm{dL}$, then restarted at one dose level lower. For all other grade 3 or 4 toxicities, treatment was withheld until resolution to no worse than grade 2; treatment was then resumed with study medications reduced by one dose level.

\section{Assessment of Efficacy and Safety:}

Complete tumor assessment was undertaken every two cycles during the initial phase therapy of the study and every 12 weeks during the maintenance phase. Responses were assessed by World Health Organization criteria. Toxicity was graded and assessed every cycle using the National Cancer Institute common toxicity criteria, version 2 .

\section{Statistical Analysis:}

Pretreatment characteristics of both treatment arms were compared using the Chi- square test. The objective response rate was defined as the percentage of patients achieving a Complete Response (CR) or Partial Response (PR) at the end of the initial therapy phase. Response rates and incidence of toxicity were compared using the Chi- square test. Toxicities by grade were tabulated by each treatment arm during the initial and maintenance phases. Time to disease progression was measured from the date of entry into the trial up to time of treatment failure or disease progression and was characterized using the Kaplan-Meier equations. The overall survival rate was measured from the date of entry into the trial up to time of death or up to the date of the last follow-up. Overall survival rate was also characterized using Kaplan-Meier method. Survival curves were calculated from the life tables. Significance of differences between survivals curves were calculated using the Kaplan- Meier method. The 1-year and 2-year survival and progression-free survival were calculated using the Chi-square test. Mann-Whitney U test was used to compare the median survival and median time to progression in both treatment groups. Confidence intervals (CIs) were calculated using Cox's proportional hazard model. $P$-value is considered significant if it is $<0.05$. 
Kasr-El-Aini Journal Of Clinical Oncology And Nuclear Medicine

\begin{tabular}{l|ll} 
Vol. 7 No. 3-4 2011 & Weekly Paclitaxel Combined with...
\end{tabular}

Informed consent was obtained from all patients, and ethical committee approved was received by our participating center.

The randomization scheme was a permuted block design with an equal probability of assignment to either treatment arms.

The primary efficacy end point was Overall Response Rate (ORR). The secondary efficacy end points were overall patient survival and toxicity.

\section{RESULTS}

\section{Patient characteristics:}

Between January 2003 and October 2008, 90 previously untreated elderly patients with advanced NSCLC were randomized to either paclitaxel $90 \mathrm{mg} / \mathrm{m}^{2}$ weekly for 3 of 4 weeks with carboplatin (area under the curve $\{$ AUC $\}=6)$ on day 1 (arm 1 ); or paclitaxel 200 $\mathrm{mg} / \mathrm{m}^{2}$ with carboplatin $(\mathrm{AUC}=6)$ on day 1 every 3 weeks (arm 2). Four patients (three patients in arm 1 and one patient in arm 2) were excluded from our randomized study because they could not be subsequently contacted. Only 86 patients (42 patients in arm 1 and 44 patients in arm 2) completed at least two cycles of study treatment and were assessable for survival, tumor response and toxicity. Progression of disease was by far the most common reason for discontinuation in initial phase ( 8 patients in arm 1 and 18 patients in arm 2). After four cycles of chemotherapy, 60 patients with objective response or stable disease (34 patients in arm 1 and 26 patients in arm 2) were randomized to weekly paclitaxel $\left(70 \mathrm{mg} / \mathrm{m}^{2}, 3\right.$ of 4 weeks $)$ or observation as maintenance therapy.

Patient baseline characteristics for the initial therapy phase were comparable across both treatment arms (Table 1). There was higher percentage of males than females in each treatment arm, with $66.7 \%$ males in arm 1 versus $70.7 \%$ males in arm 2 . Median age was 68 years (range, 65-76 years) in arm 1 versus 69 years (range, 65-77 years) in arm 2. The percentage of patients with an ECOG PS of 0 or 1 to 2 was $85.7 \%$ and $14.3 \%$ in arm 1 versus $86.4 \%$ and $13.6 \%$ in arm 2, respectively. Stage IIIB was found in $38.1 \%$ in arm 1 versus $40.9 \%$ in arm 2 however, stage IV was found in $61.9 \%$ in arm 1 versus $59.1 \%$ in arm 2 . thirty-two $(76.2 \%)$ patients in weekly group versus twenty-four $(54.5 \%)$ patients in the 3-weekly group received the planned number of treatment cycles.

\section{Efficacy:}

The objective response rate observed at the end of initial therapy was $42.9 \%$ for arm 1 versus $31.8 \%$ for arm 2, the difference was statistically insignificant
( $P=0.074$; Hazard Ratio: 0.607; 95\% CI: 0.462-5.586). Stable disease was $38.1 \%$ in arm 1 versus $27.3 \%$ in arm 2 however; disease progression was $19 \%$ in arm 1 versus $40.9 \%$ in arm 2. The control rate (including CR, PR, and SD) was $81 \%$ in arm 1 versus $59.1 \%$ in arm 2 , the difference was statistically significant $(\mathrm{P}=0.038$; Hazard Ratio: 0.838; 95\% CI: 0.525-3.338); (Table 2).

After a median follow-up of 18 months, median survival time was 10.8 months (range: $4-37$ months; $95 \%$ CI: 4.819-16.781) for arm 1 versus 9 months (range: 3-29 months; 95\%CI: 5.338-12.662) for arm 2 ( $\mathrm{P}=0.225$; $\mathrm{X} 2$ : 1.470); (Table 3). 1-year and 2-year survival rates were $47.6 \%$ and $28.6 \%$ for arm 1 versus $36.4 \%$ and $22.7 \%$ for arm $2(P=0.543$; Hazard Ratio: 0.629 ; 95\% CI: 0.186-2.129, $P=0.671$; Hazard Ratio: 0.347; 95\% CI: 0.614-2.957); (Figure 1). Median time to disease progression was 7 months (range: 2.5 -20 months; 95\% CI: 3.686-10.314) for arm 1 versus 5.6 months (range: 2-13 months; 95\% CI: 2.077- 9.123) for arm 2 $(P=0.120$; X2: 0.960); (Table 3). 1-year progression-free survival was $23.5 \%$ for arm 1 versus $15.3 \%$ for arm 2 $(P=0.067$; Hazard Ratio: 0.425; 95\% CI: 0.069 - 2.613); (Figure 2).

On univariate analyses of the various efficacy parameters by prognostic factors including disease stage and ECOG PS. As regard response rate, significant differences between the arms were noted only for patients with stage IIIB disease and those with ECOG PS 0/1. Patients in arm 1 who had stage IIIB disease achieved an ORR of $43.8 \%$ compared with the $22.2 \%$ ORR obtained in arm $2(P=0.03)$. Response rates of $44.4 \%$ and $26.3 \%$, were achieved by patients in arm 1 and arm 2, respectively with ECOG PS 0 to $1(P=0.034)$. The median time to disease progression was significantly higher for arm 1 than arm 2 for patients with stage IIIB NSCLC (8.2 versus 6.1 months, $P=0.041$ ) and ECOG PS 0 to 1 ( 7.9 versus 5.9 months, $P=0.045$ ). The median survival time for patients with stage IIIB disease was greater on arm 1 than on arm 2 (11 versus 9.9 months, $P=0.048$ ). No other subgroup comparisons were significantly different for median time to progression or median survival time. Although the differences were not statistically significant, it is notable that 1-year survival rates were greater for arm 1 than for arm 2 across all subgroups examined. However on multivariate analysis, no subgroup comparisons were significantly different for response, median time to progression and median survival time.

\section{Toxicity:}

There was no evidence of excessive toxicity for elderly patients treated with the combination regimens. The hematological and non-hematological toxicities are described in (Table 4). Neutropenia was the predominant hematological toxicity. Grade 3/4 neutropenia occurred at a higher incidence rate in patients on arm $2(22.7 \%)$ 
compared with patients on arm $1(14.3 \%) ;(P=0.31)$. Febrile neutropenia occurred in $4.7 \%$ of patients on arm 1 versus $9.1 \%$ of patients on arm $2 ;(P=0.89)$. Grade $3 / 4$ thrombocytopenia occurred in $19 \%$ of patients on arm 1 versus $4.5 \%$ of patients on $\operatorname{arm} 2$; $(\mathrm{P}=0.036)$. Grade $3 / 4$ anemia was more common in arm $1(23.8 \%)$ than in arm $2(9.1 \%) ;(P=0.01)$. Non-hematologic toxicities were mild in both treatment arms and there were no major differences in the non-hematologic toxicity profiles between the two treatment arms. Fatigue and alopecia were the most common non-hematological treatment-related toxicity. Patients on arm 2 experienced more severe fatigue $(22.7 \%$ versus $4.7 \%$ on arm 2 and 1 respectively; $P=0.021)$ and grade $1 / 2$ alopecia $(63.6 \%$ versus $42.8 \%$ on arm 2 and 1 respectively; $P=0.021$ ). Grades 2 and 3 neurotoxicity, including neuropathy, peripheral neuritis, neuritis and paresthesia were more prevalent in patients on arm $2(13.6 \%)$, but the incidence was lower for arm $1(4.7 \%) ;(P=0.06)$. Nausea and emesis were also less frequent on the weekly schedule. Toxicity was the reason for treatment discontinuation in $13.6 \%$ of patients given the 3 -weekly regimen compared with $4.7 \%$ of those given the weekly regimen. Of these, the majority of patients withdrew consent because of toxicity.

After four cycles of chemotherapy, those with objective response or stable disease (60 patients) were randomized to weekly paclitaxel $\left(70 \mathrm{mg} / \mathrm{m}^{2}, 3\right.$ of 4 weeks; 36 patients) or observation ( 24 patients) as maintenance therapy. The median time to disease progression were 8.5 months (range: 3-20 months) for the paclitaxel group and 3.6 months (range: 2-13 months) for patients on the observation group $(P=0.001)$. No grade 4 hematologic and non-hematologic toxicities reported in the maintenance phase. Progression was the most common reason for discontinuation of maintenance therapy and only ten patients discontinued maintenance therapy because of toxicity.

Table 1: Patients Characteristics.

\begin{tabular}{|c|c|c|c|c|c|}
\hline \multirow{3}{*}{ Parameter } & \multicolumn{2}{|c|}{ Weekly Paclitaxel } & \multicolumn{2}{|c|}{ 3-weeks Paclitaxel } & \multirow{3}{*}{$P$-value } \\
\hline & No. & $\%$ & No. & $\%$ & \\
\hline & \multicolumn{2}{|c|}{$n=42$} & \multicolumn{2}{|c|}{$n=44$} & \\
\hline \multicolumn{6}{|l|}{ Age: } \\
\hline $65-70$ years & 26 & 61.9 & 26 & 59.1 & 0.821 \\
\hline$>70$ years & 16 & 38.1 & 18 & 40.9 & \\
\hline Median & \multicolumn{2}{|c|}{68} & \multicolumn{2}{|c|}{69} & 0.931 \\
\hline Range & \multicolumn{2}{|c|}{$65-76$} & \multicolumn{2}{|c|}{$65-77$} & \\
\hline \multicolumn{6}{|l|}{ Sex: } \\
\hline Male & 28 & 66.7 & 32 & 70.7 & 0.792 \\
\hline Female & 14 & 33.3 & 12 & 27.3 & \\
\hline \multicolumn{6}{|l|}{ Stage: } \\
\hline IIIB & 16 & 38.1 & 18 & 40.9 & 0.912 \\
\hline IV & 26 & 61.9 & 26 & 59.1 & \\
\hline \multicolumn{6}{|l|}{ Performance status: } \\
\hline PS 0\&1 & 36 & 85.7 & 38 & 86.4 & 0.936 \\
\hline PS 2 & 6 & 14.3 & 6 & 13.6 & \\
\hline \multicolumn{6}{|l|}{ Pathology: } \\
\hline Squamous cell carcinoma & 24 & 57.1 & 26 & 59.1 & \\
\hline Adenocarcinoma & 14 & 33.3 & 16 & 36.4 & 0.789 \\
\hline Large cell carcinoma & 4 & 9.6 & 2 & 4.5 & \\
\hline \multicolumn{6}{|l|}{ Cycles completed: } \\
\hline Total & 32 & 76.2 & 24 & 54.5 & 0.072 \\
\hline Median & \multicolumn{2}{|c|}{4 (range: $3-4$ ) } & \multicolumn{2}{|c|}{4 (range: $2-4$ ) } & 0.968 \\
\hline Maintenance therapy: & 20 & 58.8 & 16 & 61.5 & 0.442 \\
\hline Maintenance paclitaxel & 14 & 41.2 & 10 & 38.5 & \\
\hline
\end{tabular}


Table 2: Tumor response in both treatment groups.

\begin{tabular}{lccccc}
\hline \multirow{2}{*}{ Response } & \multicolumn{2}{c}{$\begin{array}{c}\text { Weekly } \\
\text { Paclitaxel }\end{array}$} & \multicolumn{2}{c}{$\begin{array}{c}\text { 3-weeks } \\
\text { Paclitaxel }\end{array}$} & \multirow{2}{*}{ P-value } \\
\cline { 2 - 5 } & No. & \% & No. & \% & \\
\hline Overall response & 18 & 42.9 & 14 & 31.8 & \multirow{2}{*}{0.074} \\
\hline Complete response & 2 & 11.4 & 0 & 0 & \\
\hline Partial response & 16 & 38.1 & 14 & 31.8 & \\
\hline Stable disease & 16 & 38.1 & 12 & 27.3 & \\
\hline Progressive disease & 8 & 19 & 18 & 40.9 & \\
\hline Control rate* & 34 & 81 & 26 & 59.1 & 0.038 \\
\hline
\end{tabular}

*Including complete response, partial response and stable disease.
Table 3: Efficacy outcomes in both treatment groups.

\begin{tabular}{|c|c|c|c|}
\hline Parameter & $\begin{array}{l}\text { Weekly Paclitaxel } \\
\text { (months) }\end{array}$ & $\begin{array}{c}\text { 3-weeks Paclitaxel } \\
\text { (months) }\end{array}$ & P-value \\
\hline \multirow[t]{2}{*}{$\begin{array}{l}\text { Median time to } \\
\text { progression }\end{array}$} & 7 & 5.6 & 0.120 \\
\hline & Range: $(2.5-20)$ & Range: (2-13) & \\
\hline \multirow[t]{2}{*}{$\begin{array}{l}\text { Median overall } \\
\text { survival }\end{array}$} & 10.8 & 9 & 0.225 \\
\hline & Range: (4-37) & Range: (3- 29) & \\
\hline
\end{tabular}

Table 4: Patients with hematologic and non hematologic toxicities in both treatment arms.

\begin{tabular}{lccc}
\hline Toxicities & Weekly Paclitaxel (\%) & 3-weeks Paclitaxel (\%) & P-value \\
\hline Hematologic Toxicities: & Grade3/4 & Grade3/4 & \\
\hline Neutropenia & & & 0.31 \\
\hline Febrile neutropenia & 14.3 & 22.7 & 0.89 \\
\hline Anemia & 4.7 & 9.1 & 0.01 \\
\hline Thrombocytopenia & 23.8 & 9.1 & 0.036 \\
\hline Nonhematologic Toxicities: & 19 & 4.5 & \\
\hline Nausea & & & 0.87 \\
\hline Vomiting & 4.7 & 9.1 & 0.92 \\
\hline Peripheral neuropathy* & 4.7 & 9.1 & 0.062 \\
\hline Fatigue & 4.7 & 13.6 & 0.021 \\
\hline Alopecia & 4.7 & 22.7 & \\
\hline
\end{tabular}

* Peripheral neuropathy was grade 2 and 3 , no grade 4 .

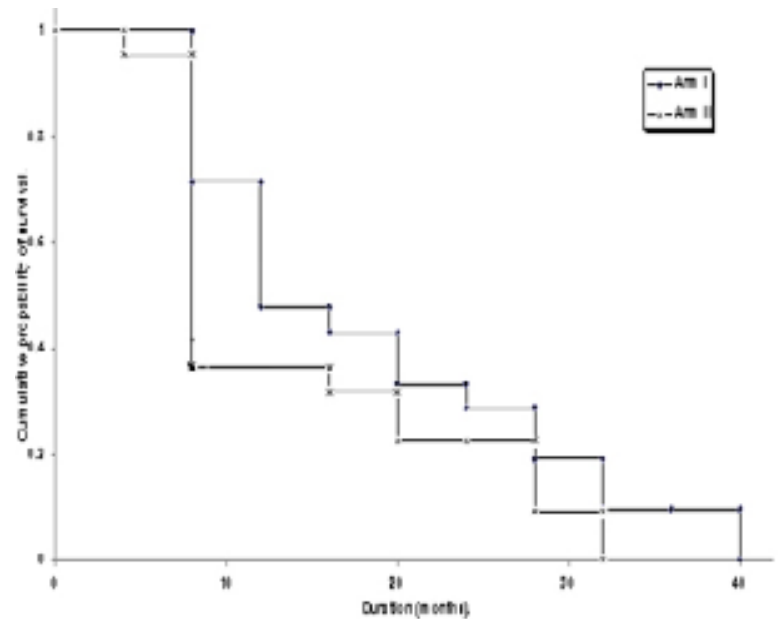

Figure 1: Survival curve f or 86 elderly patients treated with paclitaxel- based regimens. The median survival was 10.8 months in arm I and 9 months in arm II.

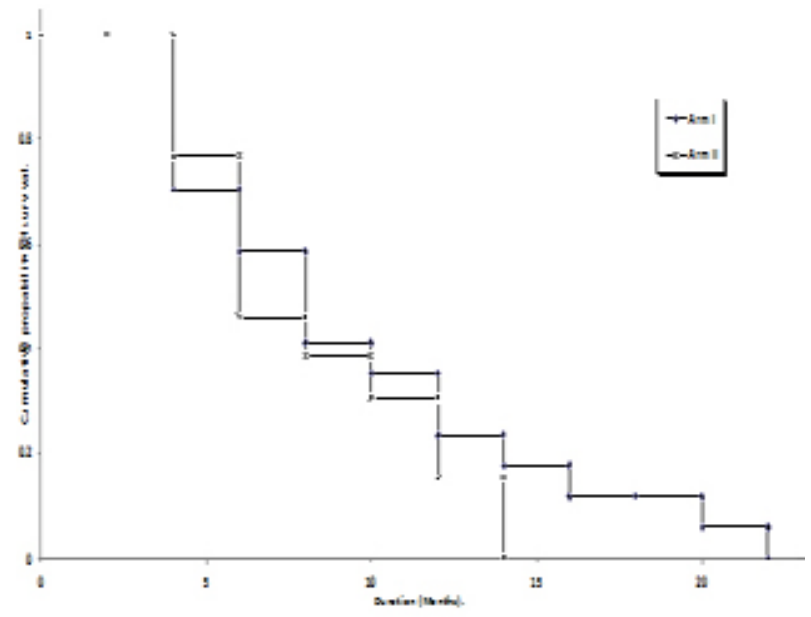

Figure 2: Time to diseas e progres sion among 86 elderly patients treated with paclitaxel- based regimens. The median time to disease progress in was 7 months in arm I and 5.6 months in arm II. 
Kasr-El-Aini Journal Of Clinical Oncology And Nuclear Medicine

Vol. 7 | No. 3-4 2011

\section{DISCUSSION}

Platinum-based chemotherapy has become the cornerstone of therapy for patients with advanced NSCLC. However, the efficacy of platinum-based chemotherapy has not been evaluated adequately in elderly patients by prospective trials. To date, the only prospectively planned evaluation of platinum-based chemotherapy in elderly patients was conducted in the CALGB 9730 trial $^{13}$. This was a randomized comparison between paclitaxel administered alone or in combination with carboplatin for patients with advanced NSCLC. Approximately $27 \%$ of the patients who participated in this study were older than 70 years. The study design allowed for stratification of patients by age $(>70$ years versus $<70$ years $)$. The response rate and survival rates noted in the elderly patients were comparable to those of younger patients in this study. There was a higher incidence of leucopenia, sepsis and febrile neutropenia in elderly patients. The other toxicities were comparable to that of younger patients. However, because of the smaller number of elderly patients in the study, these observations did not reach statistical significance. Similar observations have been made by retrospective analyses of outcome for elderly patients from randomized trials conducted in advanced $\mathrm{NSCLC}^{9,31}$. Langer et al., conducted a subset analysis of patients who participated in the ECOG 1594 trial that evaluated four different chemotherapeutic regimens for the treatment of advanced NSCLC ${ }^{31}$. Of the 1207 patients enrolled to the study, $227(20 \%)$ were older than 70 years and nine patients $1 \%$ were older than 80 years. Delivery of chemotherapy was comparable for the younger than 70 and 70 years or older age groups. Approximately $34 \%$ of the younger patients completed the planned six cycles of chemotherapy, compared with $30 \%$ of the elderly cohort. The median survival duration was 8.15 and 8.25 months for the younger and elderly cohorts, respectively. On the basis of these results, the authors concluded that elderly patients with a good performance status (ECOG PS 0/1) tolerate and benefit from systemic chemotherapy similar to younger patients.

To improve the overall tolerability of the taxanes in the elderly patients, weekly schedules of both paclitaxel and docetaxel have been developed ${ }^{23,} 32$. Promising efficacy without an appreciable increase in toxicity was noted from these studies. Single-agent paclitaxel given as a 3-h infusion every 3-4 weeks in patients with advanced NSCLC has produced response rates of $11-38 \%$ and median survival times of 6.7-11 months ${ }^{32}$. Because the antiproliferative activity of paclitaxel is cell cycle specific, prolonging exposure to the drug above a threshold concentration should ultimately be more efficacious than short-term
Hala Mohamed El-Shenshawy et al.

exposure to higher drug concentrations. The relevance of this hypothesis has been supported by in vitro experiments with a variety of cell lines and suggested by the results of clinical studies ${ }^{33,34}$. In a phase II study, Fidias et al., treated elderly NSCLC patients with a weekly dose of paclitaxel $\left(90 \mathrm{mg} / \mathrm{m}^{2}\right.$ for 6 of 8 weeks $)^{23}$. A promising response rate $(23 \%)$ and median survival (10.2 months) were noted without excessive toxicity. It has been possible to combine weekly paclitaxel with carboplatin ${ }^{35}$. Favorable efficacy with this combination was noted by a phase II study that was restricted to the elderly and patients with poor performance status ${ }^{36}$. In another phase II study, an attenuated dose of paclitaxel was administered to elderly patients in combination with carboplatin. This regimen resulted in a response rate of $40 \%$ and a median time to progression of 5.5 months $^{37}$.

In our randomized study that compares weekly schedule of paclitaxel combined with carboplatin with standard every 3 -weeks schedule of paclitaxel combined with carboplatin for elderly previously untreated patients with advanced NSCLC, the regimen with better therapeutic index was weekly paclitaxel $(90 \mathrm{mg} /$ $\mathrm{m}^{2}$ administered for 3 of 4 weeks) in combined with carboplatin (AUC $=6 \mathrm{mg} / \mathrm{ml} / \mathrm{min}$ every 4 weeks). This study results in considerable improvement in overall response rate of $42.9 \%$ in arm 1 (weekly schedule of paclitaxel combined with carboplatin) versus $31.8 \%$ in arm 2 (standard every 3-weeks schedule of paclitaxel combined with carboplatin) in elderly patients with advanced NSCLC. These findings agree with many trials that reported an overall response rate ranging from $11 \%$ to $43.5 \%$ in weekly schedule $8,20-23,28,38-40$ and overall response rate ranging from $17 \%$ to $25 \%$ in 3 -weeks schedule $^{25-27}$. Our results are slightly higher than some study as our regimen used as first-line treatment in previously untreated patients and the median age was slightly lower than in those studies. However, recent randomized phase II trial comparing weekly paclitaxel combined with carboplatin with standard paclitaxel combined with carboplatin in elderly patients ( $\geq 70$ years) with advanced NSCLC reported high overall response rate $55 \%$ and $53 \%$, respectively ${ }^{29}$.

The median survival time, 1-year and 2-year survival were longer in weekly schedule than 3-weekly schedule, but the differences not reach a statistically significant difference in our study. These findings incorporated with the results of Suresh et al. ${ }^{28}$ and Sakakibara et al. ${ }^{29}$ Although the differences in the duration of treatment cycle between the two arms ( 4 and 3 weeks, respectively, for arms 1 and 2) could have contributed to differences in median TTP, the overall survival and 1-year survival results are comparable between the two arms. The lower incidence of grade $2 / 3$ neuropathy was achieved with 
Kasr-El-Aini Journal Of Clinical Oncology And Nuclear Medicine

\begin{tabular}{l|lll} 
Vol. 7 No. 3-4 2011 & Weekly Paclitaxel Combined with...
\end{tabular}

the weekly paclitaxel regimen despite the same doseintensity of paclitaxel on both the arms.

Ukena et al. ${ }^{41}$ who compared weekly paclitaxel combined with carboplatin with standard regimen of 3 -weeks paclitaxel with carboplatin had similar results to our study, they noted lower incidence of grade 2 or worse sensory neuropathy with the weekly regimen. Grade 2 or worse. Neutropenia was also less common with the weekly schedule ( $35 \%$ v 53\%). Socinski et al., (42 reported that although efficacy was similar between the two arms, grade 3/4 thrombocytopenia and grade 2-4 anemia were significantly more in weekly arm, myalgia/arthralgia was less common with the weekly arm and there was a trend toward a lower incidence of neuropathy and neutropenia. These findings are in accordance with our results. Furthermore, patients in the standard arm reported significantly more taxane-related adverse effects on the Functional Assessment of Cancer Therapy (FACT) taxane subscale. Taken together, the weekly regimen of paclitaxel in combination with carboplatin can be considered an evidence-based therapeutic option for front-line therapy of advanced $\mathrm{NSCLC}^{43}$.

Neuropathy has always been a concern with the carboplatin and paclitaxel doublet. In the original phase III trials testing this regimen ${ }^{25,26,42,44,45}$, rates of grade $\geq 3$ neuropathy ranged from $11 \%$ to $17 \%$. These initial trials usually treated for six or more cycles. The neuropathy associated with this regimen is typically cumulative. In an analysis of the duration of therapy trial performed with carboplatin and paclitaxel, 19.9\% of patients experienced grade $\geq 2$ neuropathy during the first four cycles of therapy, while $43 \%$ of patients experienced grade $\geq 2$ neuropathy by the time they had received eight cycles of therapy. Both this trial and the trial by Belani et al. ${ }^{46}$ limited the duration of therapy with this regimen to four cycles and had rates of grade $\geq 3$ neuropathy of $3-6 \%$, which was not statistically different when comparing every 3 weeks versus weekly paclitaxel infusion schedules. These data strongly support the cumulative aspect of neuropathy with this regimen and show that severe neuropathy is uncommon with this regimen when appropriate durations of therapy are used in this patient population.

Another objective of our study was to evaluate the feasibility of maintenance therapy with weekly paclitaxel after four cycles of combination chemotherapy. Four cycles of chemotherapy are considered optimal for elderly patients with advanced-stage NSCLC. Continuation of combination chemotherapy beyond four to six cycles results in cumulative toxicity without any improvement in efficacy ${ }^{47,48}$. This raises the question of whether administration of a single agent as maintenance therapy might be beneficial because it is associated with minimal cumulative toxicity. In randomized phase II study conducted by Belani et al. ${ }^{38}$ with weekly paclitaxel regimens, patients randomly assigned to maintenance weekly paclitaxel seemed to have improved efficacy. Therefore, we included weekly paclitaxel as maintenance therapy for patients in both arms of the study after four cycles of combination therapy. Maintenance therapy with paclitaxel delayed the time to disease progression (8.2 versus 4.8 months) and yielded a greater median survival time (13.9 versus 8.1 months). These findings are in accordance with our results, as the maintenance therapy with paclitaxel delayed the time to disease progression (8.5 versus 3.6 months) and yielded also a greater median survival time (19.5 versus 9.5 months). Despite these interesting results, no definitive statement can be made regarding the role of weekly maintenance treatment with paclitaxel. If the study sample was larger, there is a possibility that a significant effect may have been identified. Therapy beyond four cycles with the same regimen may not be beneficial in elderly patients with advanced NSCLC ${ }^{47-49}$, but the role of nontoxic, low doses of a single agent in this setting still remains an open question.

\section{CONCLUSION}

Our trial confirms the efficacy and safety of weekly paclitaxel combined with carboplatin schedule that might be considered a reasonable choice in elderly patients with advanced NSCLC.

\section{REFFERENCES}

1. Jemal A, Siegel R, Ward E, Hao Y, Xu J, Murray T, et al. Cancer statistics, 2008. CA Cancer J.Clin. 2008;58(2): 71-96.

2. Glassberg AB, Cornett P. Lung: Non-small cell. In: Dollinger M, Rosenbaum EH, Cable G, Rosenbaum EH, editors. Everyone's guide to cancer therapy. 2nd ed.: Andrews Mcmeel Pub.; 1994. p. 469-75.

3. Gridelli C, Pertone F, Monfardini S. Lung cancer in the elderly. Eur.J.Cancer 1997;33(14):2313-4.

4. Havlik RJ, Yancik R, Long S, Ries L, Edwards B. The National Institute on Aging and the National Cancer Institute SEER collaborative study on comorbidity and early diagnosis of cancer in the elderly. Cancer 1994;74 (7 Suppl.):2101-6.

5. Hutchins LF, Unger JM, Crowley JJ, Coltman Jr. CA, Albain KS. Underrepresentation of patients 65 years of age or older in cancer-treatment trials. N.Engl.J.Med. 1999;341(27):2061-7.

6. Socinski MA, Morris DE, Masters GA, Lilenbaum R. Chemotherapeutic management of stage IV non-small cell lung cancer. Chest 2003;123(1 Suppl.):226S-43S. 
7. Bunn Jr. PA, Lilenbaum R. Chemotherapy for elderly patients with advanced non-small-cell lung cancer. J.Natl. Cancer Inst. 2003;95(5):341-3.

8. Ramalingam S, Barstis J, Perry MC, La Rocca RV, Nattam $\mathrm{SR}$, Rinaldi D, et al. Treatment of elderly non-small cell lung cancer patients with three different schedules of weekly paclitaxel in combination with carboplatin: Subanalysis of a randomized trial. J.Thorac.Oncol. 2006;1(3):240-4.

9. Langer CJ, Manola J, Bernardo P, Kugler JW, Bonomi P, Cella D, et al. Cisplatin-based therapy for elderly patients with advanced non-small-cell lung cancer: Implications of Eastern Cooperative Oncology Group 5592, a randomized trial. J.Natl.Cancer Inst. 2002;94(3):173-81.

10. Frasci G, Lorusso V, Panza N, Comella P, Nicolella G, Bianco A, et al. Gemcitabine plus vinorelbine versus vinorelbine alone in elderly patients with advanced non-small-cell lung cancer. J.Clin.Oncol. 2000; 18(13):2529-36.

11. Gridelli C. Effects of vinorelbine on quality of life and survival of elderly patients with advanced non-small-cell lung cancer. J.Natl.Cancer Inst. 1999;91(1):66-72.

12. Gridelli C, Perrone F, Gallo C, Cigolari S, Rossi A, Piantedosi F, et al. Chemotherapy for elderly patients with advanced non-small-cell lung cancer: The Multicenter Italian Lung cancer in the Elderly Study (MILES) phase III randomized trial. J.Natl.Cancer Inst. 2003; 95(5):362-72.

13. Lilenbaum RC, Herndon JE, List M. Single agent versus combination chemotherapy in patients with advanced non-small cell lung cancer: A CALGB randomized trial of efficacy, quality of life and cost-effectiveness. Proc. Am.Soc.Clin.Oncol. 2002;2:1a.

14. Sederholm C. Gemcitabine compared with gemcitabine plus carboplatin in advanced non-small cell lung cancer: A phase III study by the Swedish Lung Cancer Study Group. Proc.Am.Soc.Clin.Oncol. 2002;21:291a.

15. Wozniak AJ, Crowley JJ, Balcerzak SP, Weiss GR, Spiridonidis $\mathrm{CH}$, Baker LH, et al. Randomized trial comparing cisplatin with cisplatin plus vinorelbine in the treatment of advanced non-small-cell lung cancer: A Southwest Oncology Group study. J.Clin.Oncol. 1998;16(7):2459-65.

16. Sandler AB, Nemunaitis J, Denham C, Von Pawel $\mathrm{J}$, Cormier Y, Gatzemeier U, et al. Phase III trial of gemcitabine plus cisplatin versus cisplatin alone in patients with locally advanced or metastatic non-smallcell lung cancer. J.Clin.Oncol. 2000;18(1):122-30.

17. Belotti D, Vergani V, Drudis T, Borsotti P, Pitelli $\mathrm{MR}$, Viale $\mathrm{G}$, et al. The microtubule-affecting drug paclitaxel has antiangiogenic activity. Clin.Cancer Res. 1996;2(11):1843-9.

18. Klauber N, Parangi S, Flynn E, Hamel E, D'Amato RJ. Inhibition of angiogenesis and breast cancer in mice by the microtubule inhibitors 2-methoxyestradiol and taxol. Cancer Res. 1997;57(1):81-6.
19. Dordunoo SK, Jackson JK, Arsenault LA, Oktaba AMC, Hunter WL, Burt HM. Taxol encapsulation in poly(å-caprolactone) microspheres. Cancer Chemother. Pharmacol. 1995;36(4):279-82.

20. Chang A, Boros L, Asbury R, Rubins J, Hui L. Weekly moderate-dose paclitaxel in stage IV Non-Small Cell Lung Cancer (NSCLC). Proc.Am.Soc.Clin.Oncol. 1998;17:A1806.

21. Akerley W, Herndon J, Merrill E, Lyss A, Kindler H, Savarese D, et al. Phase II trial of weekly paclitaxel for advanced Non-Small Cell Lung Cancer (NSCLC). Proc. Am.Soc.Clin.Oncol. 1999; 18:A1783.

22. Rossi D, Dennetta D, Ugolini M, Alessandroni P, Catalano $\mathrm{V}$, Fedeli SL, et al. Weekly paclitaxel in elderly patients (aged $\leq 70$ years) with advanced non-small-cell lung cancer: An alternative choice? Results of a phase II study. Clin.Lung Cancer 2008;9(5):280-4.

23. Fidias P, Supko JG, Martins R, Boral A, Carey R, Grossbard $\mathrm{M}$, et al. A phase II study of weekly paclitaxel in elderly patients with advanced non-small cell lung cancer. Clin. Cancer Res. 2001;7(12):3942-9.

24. Yasuda K, Igishi T, Kawasaki Y, Yamamoto M, Kato K, Matsumoto $\mathrm{S}$, et al. Phase II trial of weekly paclitaxel in previously untreated advanced non-small-cell lung cancer. Oncology 2003;65(3):224-8.

25. Schiller JH, Harrington D, Belani CP, Langer C, Sandler A, Krook J, et al. Comparison of four chemotherapy regimens for advanced non-small-cell lung cancer. N.Engl.J.Med. 2002;346(2):92-8.

26. Kelly K, Crowley J, Bunn PA, Presant CA, Grevstad $\mathrm{PK}$, Moinpour CM, et al. Randomized phase III trial of paclitaxel plus carboplatin versus vinorelbine plus cisplatin in the treatment of patients with advanced nonsmall-cell lung cancer: A Southwest Oncology Group trial. J.Clin.Oncol. 2001;19(13):3210-8.

27. Belani CP, Natale RB, Lee JS. Randomized phase II trial comparing cisplatin/etopside versus carboplatin/paclitaxel in advanced and metastatic Non-Small Cell Lung Cancer (NSCLC). Proc.Am.Soc.Clin.Oncol. 1998;17(3):A1751.

28. Ramalingam S, Perry MC, La Rocca RV, Rinaldi D, Gable PS, Tester WJ, et al. Comparison of outcomes for elderly patients treated with weekly paclitaxel in combination with carboplatin versus the standard 3-weekly paclitaxel and carboplatin for advanced nonsmall cell lung cancer. Cancer 2008;113(3):542-6.

29. Sakakibara T, Inoue A, Sugawara S, Maemondo M, Ishida $\mathrm{T}$, Usui $\mathrm{K}$, et al. Randomized phase II trial of weekly paclitaxel combined with carboplatin versus standard paclitaxel combined with carboplatin for elderly patients with advanced non-small-cell lung cancer. Ann.Oncol. 2010;21(4):795-9.

30. Bocci G, Nicolaou KC, Kerbel RS. Protracted lowdose effects on human endothelial cell proliferation and survival in vitro reveal a selective antiangiogenic window for various chemotherapeutic drugs. Cancer Res. 2002;62(23):6938-43. 
31. Langer CI, Vangel M, Schiller J. Age-specific subanalysis of BCOG 1594: Fit elderly patients(70-80 ys) with NSCLC do as well as younger pts ( $<70$ years). Proc.Am.Soc.Clin. Oncol. 2003;22:639.

32. Hainsworth JD, Burris III HA, Litchy S, Morrissey LH, Barton $\mathrm{JH}$, Bradof JE, et al. Weekly docetaxel in the treatment of elderly patients will advanced nonsmall cell lung carcinoma: A Minnie Pearl Cancer Research Network Phase II Trial. Cancer 2000;89(2):328-33.

33. Georgiadis MS, Russell EK, Gazdar AF, Johnson BE. Paclitaxel cytotoxicity against human lung cancer cell lines increases with prolonged exposure durations. Clin. Cancer Res. 1997;3(3):449-54.

34. Zhan Z, Scala S, Monks A, Hose C, Bates S, Fojo T. Resistance to paclitaxel mediated by P-glycoprotein can be modulated by changes in the schedule of administration. Cancer Chemother.Pharmacol. 1997;40(3):245-50.

35. Ramanath RK, Capozzoli MJ, Trump DL, Jacobs S, Belani CP. Escalating doses of weekly paclitaxel in combination with carboplatin: A phase I study in advanced malignancies. Proc.Am.Soc.Clin.Oncol. 1999;16:166.

36. Marsland TA, Garfield DH, Khan MM, Look RM, Boehm KA, Asmar L. Sequential versus concurrent paclitaxel and carboplatin for the treatment of advanced non-small cell lung cancer in elderly patients and patients with poor performance status: Results of two Phase II, multicenter trials. Lung Cancer 2005;47(1):111-20.

37. Choi IS, Kim BS, Park SR, Lee SY, Kim DY, Kim JH, et al. Efficacy of modified regimen with attenuated doses of paclitaxel plus carboplatin combination chemotherapy in elderly and/or weak patients with advanced nonsmall cell lung cancer. Lung Cancer 2003;39(1): 99-101.

38. Belani CP, Barstis J, Perry MC, La Rocca RV, Nattam SR, Rinaldi $\mathrm{D}$, et al. Multicenter, randomized trial for stage IIIB or IV non-small-cell lung cancer using weekly paclitaxel and carboplatin followed by maintenance weekly paclitaxel or observation. J.Clin.Oncol. 2003;21(15):2933-9.

39. Pujol JL, Milleron B, Molinier O, Quoix E, Depierre A, Breton JL, et al. Weekly paclitaxel combined with monthly carboplatin in elderly patients with advanced non-small cell lung cancer: A multicenter phase II study. J.Thorac. Oncol. 2006;1(4):328-34

40. Kallab AM, Nalamolu Y, Dainer PM, Jillella AP. A phase II study of weekly paclitaxel and carboplatin in previously untreated patients with advanced non-small-cell lung cancer. Med.Oncol. 2005;22(2):145-51.
41. Ukena D, Schroeder M, Dittrich I. Phase III randomized trial comparing Paclitaxel Carboplatin (PC) every 3 weeks with weekly paclitaxel/carboplatin in patients (pts) with advanced Non Small Cell Lung Cancer (NSCLC). Proc. Am.Soc.Clin.Oncol. 2003;22:A2506.

42. Socinski MA, Ivanova A, Bakri K, Wall J, Baggstrom MQ, Hensing TA, et al. A randomized phase II trial comparing every 3-weeks carboplatin/paclitaxel with every 3-weeks carboplatin and weekly paclitaxel in advanced non-small cell lung cancer. Ann.Oncol. 2006;17(1):104-9.

43. Belani CP, Ramalingam S, Perry MC, LaRocca RV, Rinaldi D, Gable PS, et al. Randomized, phase III study of weekly paclitaxel in combination with carboplatin versus standard every-3-weeks administration of carboplatin and paclitaxel for patients with previously untreated advanced non-smallcell lung cancer. J.Clin.Oncol. 2008;26(3):468-73.

44. Scagliotti GV, De Marinis F, Rinaldi M, Crinò L, Gridelli $\mathrm{C}$, Ricci S, et al. Phase III randomized trial comparing three platinum-based doublets in advanced non-small-cell lung cancer. J.Clin.Oncol. 2002;20(21):4285-91.

45. Socinski MA, Schell MJ, Peterman A, Bakri K, Yates S, Gitten R, et al. Phase III trial comparing a defined duration of therapy versus continuous therapy followed by secondline therapy in advanced-stage IIIB/IV non-small-cell lung cancer. J.Clin.Oncol. 2002;20(5):1335-43.

46. Belani CP, Larocca R, Rinaldi D. A multicenter phase III randomized trial for stage IIIB/IV NSCLC of weekly paclitaxel and carboplatin versus standard paclitaxel and carboplatin given every three weeks, followed by weekly paclitaxel. Proc.Am.Soc.Clin.Oncol. 2004;23:619.

47. Socinski MA, Schell MJ, Bakri K, Peterman A, Lee JL, Unger $\mathrm{P}$, et al. Second-line, low-dose, weekly paclitaxel in patients with stage IIIB/IV nonsmall cell lung carcinoma who fail first-line chemotherapy with carboplatin plus paclitaxel. Cancer 2002;95(6):1265-73.

48. Smith IE, O'Brien MER, Talbot DC, Nicolsan MC, Mansi JL, Hickish TF, et al. Duration of chemotherapy in advanced non-small-cell lung cancer: A randomized trial of three versus six courses of mitomycin, vinblastine and cisplatin. J.Clin.Oncol. 2001;19(5):1336-43.

49. Depierre A, Quoix E, Mercier M, Breton JL, Moro Sibilot $\mathrm{D}$, Debieuvre $\mathrm{D}$, et al. Maintenance chemotherapy in advanced Non-Small Cell Lung Cancer (NSCLC): A randomized study of Vinorelbine (V) versus Observation (OB) in Patients (Pts) responding to induction therapy (French Cooperative Oncology Group). Proc.Am.Soc. Clin.Oncol. 2001;20:A1231. 